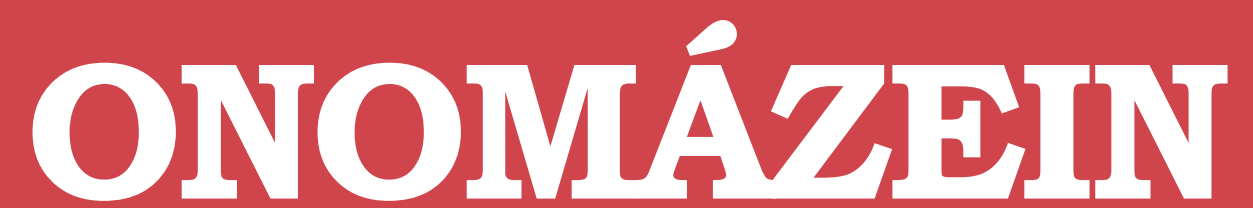

Revista semestral de lingüística, filología y traducción
PONTIFICIA UNIVERSIDAD CATÓLICA DE CHILE FACULTAD DE LETRAS

\title{
Estructura informativa y fisonomía acústica en oraciones copulativas ecuacionales ${ }^{1}$
}

Information structure and acoustic physiognomy

in equational copulative sentences

\section{Claudio Pinuer Rodríguez}

Universidad de Concepción

Chile

\section{Hernán Pérez Muñoz}

Universidad de Concepción Chile

\section{Magaly Ruiz Mella}

Universidad de La Frontera

Chile

\section{Jaime Soto-Barba}

Universidad de Concepción Chile

\section{(c) $(\mathrm{i}) \bigodot_{\mathrm{BY}}$}

Claudio Pinuer Rodríguez: Departamento de Español, Facultad de Humanidades y Arte, Universidad de Concepción. Chile. Correo electrónico: cpinuer@udec.cl

Magaly Ruiz Mella: Departamento de Lenguas, Literatura y Comunicación, Facultad de Educación, Ciencias Sociales y Humanidades, Universidad de La Frontera. Chile. Correo electrónico: mruiz@ufro.cl Hernán Pérez Muñoz: Departamento de Español, Facultad de Humanidades y Arte, Universidad de Concepción. Chile. Correo electrónico: heperez@udec.cl

Jaime Soto-Barba: Departamento de Español, Facultad de Humanidades y Arte, Universidad de Concepción.Chile. Correo electrónico: jstot@udec.cl 


\section{Resumen}

Este artículo presenta los resultados de un estudio acústico y gramatical de 21 oraciones ecuacionales o copulativas enfáticas, a través de un análisis melódico (Cantero, 2002; y Cantero y Font, 2009) seguido de una interpretación pragmática de los principales hallazgos en términos de su funcionalidad como correlatos fónicos de la fisonomía informativa que singulariza a las oraciones ecuacionales como construcciones de foco (Gutiérrez, 1997; Cid y Maluenda, 2005; NGLE 2009) especializadas en realzar un segmento oracional con independencia a su grado de novedad (dado o nuevo) y función comunicativa (contraste o ampliación).
La investigación se desarrolló bajo los principios generales del funcionalismo (Silva-Corvalán, 2001; Halliday y Matthiessen, 2004; Halliday, 2005), por lo cual los rasgos prosódicos, sintácticos y pragmáticos relevados en el análisis se consideraron pertinentes para las diversas presentaciones de la oración copulativa enfática.

Los resultados mostraron una tendencia robusta en la realización del acento enfático en posición inicial de enunciado, con independencia al tipo focal (contrastivo o neutro) y modalidad ecuacional (hendida, pseudohendida y pseudohendida inversa).

Palabras clave: oraciones ecuacionales; foco; acento enfático.

\section{Abstract}

This article presents the results of an acoustic and grammatical study of 21 equational or emphatic copulative sentences through melodic analysis (Cantero, 2002; Cantero \& Font, 2009). This study was then followed by a pragmatic interpretation of the main findings in relation to their functionality as phonic correlates of the informative structure that individualizes the equational sentences as focus constructions (Gutiérrez, 1997; Cid \& Maluenda, 2005; NGLE, 2009).

The research was conducted under the ge- neral principles of functionalism (Silva-Corvalán, 2001; Halliday \& Matthiessen, 2004; Halliday, 2005), whereby the prosodic, syntactic and pragmatic features relieved in the analysis are considered relevant in the expression of the focuser role of the emphatic copulative sentences.

The results showed a strong trend in the performance of emphatic accent in the utterance's initial position, regardless of the focal type (contrastive or neutral) and equational type (cleft, pseudocleft and pseudocleft reverse).

Keywords: equational sentences; focus; emphatic accent. 


\section{Introducción}

Las oraciones ecuacionales (clasificadas en hendidas, pseudohendidas y pseudohendidas inversas) u oraciones copulativas enfáticas en la nueva gramática académica (NGLE) son construcciones especializadas en la asignación de prominencia focal, mediante la selección y presentación de un segmento con la jerarquía de epicentro designativo (Pinuer, 2007), al margen de su grado de novedad informativa (dado o nuevo) y de su función comunicativa (contrastiva o ampliación).

Las oraciones ecuacionales, como cualquier otro mecanismo de focalidad, permiten el análisis de los procesos de articulación entre el sistema gramatical y el sistema informativo, planteado por ahora de un modo laxo, ya que no existe acuerdo en la posición del fenómeno pragmático respecto del sistema lingüístico.

Junto a la coocurrencia de elementos gramaticales e informativos, estas oraciones se realizan con otros rasgos singularizadores, particularmente en el plano suprasegmental, los cuales, no obstante su reconocida funcionalidad (Face, 2002), han sido objeto de poca atención (Cid y Maluenda, 2005) en comparación con los estudios sintácticos y pragmáticos, hecho que podría relacionarse con la tesis de que en español la prosodia tiene una limitada participación en la manifestación de focalidad (Martínez, 1999).

Así como es debatible la forma de articulación entre el plano lexicogramatical y el nivel pragmático, de igual forma es patente el desacuerdo sobre el vínculo entre sintaxis y prosodia, en términos de si se produce una interacción directa 0 , por el contrario, una relación mediada por la dimensión informativa.

Si bien nuestro estudio no se propone abordar ambas controversias, de todas formas podría entregar datos que aporten a la discusión, especialmente desde el estrato acústico, donde el problema es menos conocido. Estas y otras incertidumbres tienen en la actualidad importantes repercusiones cuando se está examinando críticamente las condiciones de diseño del sistema lingüístico para interactuar eficazmente con el sistema conceptual y el sistema sensoriomotor (Eguren y Fernández, 2004).

En el marco del análisis de la función focal o, planteado más técnicamente, de la función pragmática de focalidad, nos propusimos describir acústicamente un conjunto de oraciones ecuacionales para intentar establecer la existencia de patrones prosódicos asociados a la estructura y funcionamiento de las construcciones de foco, las cuales presentan flexibilidad linear y heterogeneidad informativa, como se verá luego.

Este artículo ofrece una síntesis del marco conceptual que sustentó la pesquisa, así como del diseño metodológico y los resultados más interesantes en torno a la posibilidad de obtener valores fónicos interpretables como correlatos acústicos de oraciones ecuacionales producidas por hablantes profesionales en paneles de radio y televisión en situación de habla formal².

Nuestro estudio se inscribe epistemológicamente en el funcionalismo dikeano (Dik, 1997), para el cual la oración (cláusula en el modelo) es una estructura organizada en tres estratos (sintáctico, semántico e informativo) que interactúan y definen las propiedades de la construcción. La dimensión segmental y suprasegmental se interpreta como una fase de producción, inseparable de la materialización del enunciado, aunque externa a su naturaleza central.

No ponemos en discusión que las oraciones ecuacionales manifiesten rasgos prosódicos que no solo las distingan, sino que también concurran en el establecimiento de variedades funcionales. Frente a lo anterior y en respuesta

2 Tanto la presentación conceptual como el análisis fueron muy enriquecidos por los valiosos comentarios recibidos en la evaluación del artículo. Agradecemos la lectura acuciosa y crítica. 
a una de las interrogantes planteadas al inicio de la sección en desarrollo, formulamos o, mejor aún, adherimos a la hipótesis de que los correlatos acústicos corresponden en mayor medida al tipo focal activado (contrastivo y neutro) y, en menor medida, a la configuración sintáctica de la magnitud (hendida, pseudohendida y pseudohendida inversa) ${ }^{3}$.

En armonía con el modelo teórico del trabajo, asignamos un rol preponderante al estrato informativo dado el carácter semiótico del sistema lingüístico. La lengua es un recurso para crear significados y permitir la interacción social y, en este sentido, las copulativas enfáticas se destacan por intensificar la función interpersonal del lenguaje (Halliday, 2005) al seleccionarse en situaciones comunicativas en las que el hablante intenta centrar la atención del destinatario en un eslabón de la cadena enunciativa, jerarquizando la significación contextual y los efectos retóricos (Martin y White, 2005)

\section{Fundamentos conceptuales}

\subsection{La función focal}

Así como las nociones de sujeto y agente caracterizan a un constituyente oracional por concordar en número y persona con el verbo y por individualizar a la entidad responsable de la predicación, la función focal realiza una porción de oración como el segmento de mayor jerarquía pragmática por su relevancia en el procesamiento informativo del destinatario. No existe obligatoriedad de que las tres funciones se produzcan en un mismo componente y, cuando ello ocurre, se establece, con pocas excepciones, una predicación no marcada en la cual se imponen factores construccionales como la contigüidad linear del verbo y sus complementos internos.

La función focal pertenece al estrato informativo, si bien en su materialización son indispensables recursos lexicogramaticales o fónicos, algunos altamente especializados como las oraciones hendidas. Según lo anterior, no parece haber espacio para dudar de la naturaleza lingüística del fenómeno informativo, tal como señala Ariel, quien estima impropia la división entre gramática y pragmática o, en su concepto, entre "codes" e "inferences" (2008: 11). Sin embargo, esta posición no es unánime, como se verá enseguida.

A nuestro modo de entender, la posibilidad de que las necesidades comunicativas puedan sobrepasar el potencial gramaticalizador del sistema lingüístico apunta en la dirección de un nivel informativo autónomo que, en determinadas circunstancias enunciativas, subordina al código y lo reajusta estructuralmente. Este principio, que recogemos de Padilla (2005), sería clave en la existencia de una tensión continua entre el sistema y las presiones informativas ejercidas sobre él, una de cuyas evidencias más directas sería la producción de enunciados de dudosa aceptabilidad (1) o agramaticales (2):

(1) ??Mucho no se van a hablar Juan con María

(2) *Juan lo trajo el libro atrasado

Por otra parte, creemos advertir en la noción de función informativa de la gramática académica (2009: 2963) una segregación más radical, al quedar justificada por "los valores discursivos que las unidades sintácticas ponen de manifiesto si se atiende a la forma en que se interpreta su contribución a los mensajes". Si nuestra apreciación es correcta, lo pragmático asomaría con posterioridad a la elección lexicogramatical, como consecuencia de factores discursivos e interpretativos.

En este trabajo se postula que las estructuras lingüísticas, y en particular las oraciones ecuacionales, incluyen en su fisonomía todas las propiedades necesarias para hacer de ellas recursos idóneos de interacción comunicativa, lo cual requiere tanto significar a través de las piezas referenciales como informar a través de los

3 Más adelante se describen ambos tipos focales. Para efectos de foco contrastivo valen los ejemplos proporcionados para ecuacionales hendidas y pseudohendidas. 
aspectos pragmáticos activados, el foco en este caso. Significar e informar son dos expresiones del carácter semiótico del fenómeno lingüístico $y$, por ello, dos perspectivas para explicar su naturaleza.

Si se tiene en cuenta que la atención es un atributo cognitivo general de la especie, no debe sorprender que el foco esté ubicado entre los fenómenos pragmáticos universales (Van Valin y LaPolla, 1997). La investigación ha comprobado que, efectivamente, todas las lenguas tienen la capacidad para codificar foco(s), jerarquizando diversos procedimientos en armonía con la naturaleza tipológica del sistema.

Es razonable suponer que, dada la ubicuidad y preponderancia de la función focal, las lenguas dispongan de un conjunto de mecanismos o dispositivos focales de variada rentabilidad y supremacía, cuya activación se encuentre regulada por factores tipológicos, cognitivos y pragmático-discursivos, en arreglo al planteamiento que desarrollaremos en seguida en torno a la realidad del español.

En esta como en otras lenguas no es tipológicamente central el factor acústico, fenómeno dependiente del grado de flexibilidad acentual de cada sistema lingüístico. La supremacía radica en el trazado oracional, noción propuesta para sistematizar las variables involucradas en la disposición de los constituyentes oracionales (Pinuer y Oteíza, 2012b), a saber, orden, linearización y alineación. La noción de orden se vincula a la disposición sintagmática de los complementos (por ejemplo, SVO) y al carácter marcado o no marcado de tal disposición (ejemplo de esto último, el taxema OVS con un predicado de logro). Por su parte, la linearización identifica el principio linear jerárquico —entre ellos, iconicidad, complejidad creciente, animacidad, relieveque determina la posición final de los complementos. En último término, la alineación describe la fisonomía linear de acuerdo con la posición de los argumentos, cuya distribución canónica es determinada por el predicado verbal.
En el ámbito cognitivo, el foco es un lugar de atención en la cadena lingüística y factor de cohesión discursiva, lo que eleva su jerarquía a un punto tal que puede cancelar rasgos matrices de una lengua, caso del orden canónico o la complejidad progresiva en español. El aseguramiento de la visibilidad y perceptibilidad del segmento focal puede plantearse en términos de principios estructurales que regulan la fisonomía de los enunciados lingüísticos. Como se ha planteado (Pinuer y Oteíza, 2012a), la activación del principio de relieve es fundamental para producir un foco y crítica para desactivar una serie de regulaciones sostenida por patrones asociados a la contigüidad funcional (principio de integridad de dominio) y el costo cognitivo ascendente (complejidad creciente), entre otros

El foco cumple un papel clave en los enunciados de predicación pragmática o marcada, los cuales se orientan con mayor fuerza al enriquecimiento informativo del destinatario, razón por la cual adquieren la configuración sintáctica acorde a la prominencia establecida por el hablante (por ejemplo, la dislocación de objetos es consecuencia sintáctica de su focalización por contraste). La operación informativa debe articularse con los niveles lingüísticos para que estos aporten los rasgos necesarios requeridos por la variedad focal activada. En el caso del mencionado foco contrastivo, las reglas distribucionales situarán el segmento en posición inicial donde quede facultado para recibir el acento enfático, el cual tiene esa ubicación como locación preferente. El mismo foco puede manifestarse a través de una oración ecuacional hendida, construcción que dejará la magnitud en una posición de similar jerarquía.

Dada la importancia que adquieren los recursos involucrados en la proyección focal, es frecuente que la función sea definida sobre la base de estos recursos, como ocurre con el acento enfático, que circunscribe el foco a una prominencia acústica, y el orden de palabras, que resalta la posición marcada como un atributo 
singularizador. Sin embargo, es indispensable separar la función del mecanismo para que la estrategia se deslinde de otros fenómenos que, si bien próximos como el énfasis y la intensificación, poseen otro estatus informativo (Pinuer, 2009)

Así como foco no es sinónimo de acento, tampoco es equivalente a información nueva, aunque tal imbricación puede llegar a ser bastante común (Hengeveld y Mackenzie, 2008). Según Dik (1997), el foco es información saliente (en su codificación) y relevante para las necesidades informativas de un destinatario. No hay problema en asociar estos requerimientos a información desconocida, con tal de no reducirla a ella, pues la diferencia entre lo nuevo y lo conocido, además de ser un fenómeno continuo, depende de las expectativas del emisor respecto de su destinatario y de la evaluación de este último.

En el sentido anterior, se hace necesario situar el fenómeno focal al interior de una dimensión pragmática más amplia, que bien puede etiquetarse como dimensión de focalidad (Pinuer, 2009), en la cual se integre junto a funciones similares, como los mencionados énfasis e intensificación, que, a diferencia del foco, no tienen como función central aumentar los niveles de informatividad y sí jerarquizar aspectos de orden estilístico e idiosincrásico. Por otra parte, en el marco de una dimensión de focalidad, focality en Dik (1997), queda mejor planteada la discriminación entre diversos tipos de focos, cuyas denominaciones heredan y reflejan la heterogeneidad del fenómeno.

En efecto, la separación entre un foco contrastivo (introducido para corregir información previa) y uno neutro (que no rectifica, sino que introduce o amplía) se apoya en el papel discursivo del componente referencial en donde se cotejan los valores de contraste y de neutralidad informativa, respectivamente. En forma análoga, cuando se distingue entre foco amplio y estrecho se tiene en cuenta si todo un grupo fónico (foco amplio) o un componente de él (foco estrecho) es realzado por el acento nuclear.

Si bien una tipología focal debe incluir las cuatro variedades antes reseñadas, es importante considerar que la distinción foco contrastivo y foco neutro jerarquiza las propiedades informativas del segmento ponderado. La segunda clasificación prioriza factores acústicos y asigna un papel complementario al plano informativo, por lo cual tiende a confundirse con fenómenos contiguos como los mencionados énfasis e intensificación que, según nuestra comprensión, no operan en el nivel propiamente designativo del enunciado.

El foco, aunque no necesariamente la función focal y la dimensión de focalidad, es explicado en las principales teorías lingüísticas contemporáneas y no solo funcionalistas (fundamentales en este trabajo). El generativismo contemporáneo ha incorporado la noción entre los primitivos sintácticos de la teoría, si bien esto no ha implicado siquiera relativizar el principio de autonomía de la sintaxis. Por ejemplo, en el Ilamado generativismo minimalista, se trate de un programa ontológico o metodológico (Eguren y Soriano, 2004), el foco se caracteriza como un objeto sintáctico más profundo que un sintagma gramatical (como el sintagma tiempo) y poseedor de todas las propiedades que determinan su aparición superficial.

Estimamos que la importancia que han cobrado las funciones pragmáticas en la teoría generativa debe ser para estudios como este un desafío en cuanto a proporcionar datos que pongan en diálogo hipótesis diferentes que se formulan para resolver el mismo problema: el lugar del fenómeno informativo en la estructura y funcionamiento de las lenguas naturales.

\subsection{Las oraciones ecuacionales}

Previo a la caracterización de las secuencias ecuacionales, es necesario dedicar algunos conceptos al conjunto de mecanismos focales disponibles en español, los que perfectamente pueden concebirse como un subsistema prag- 
magramatical en la medida que su estructura y funcionamiento manifiesta, por una parte, los principios tipológicos dominantes de una lengua y, por otra, pone en interrelación los niveles del sistema lingüístico.

Numerosos estudios (Dik, 1997; Van Valin y LaPolla, 1997; Burdach y Poblete, 2005; NGLE, 2009; Pinuer, 2009) destacan el carácter translingüístico de la focalización, ubicuidad que puede ampliarse hasta los niveles de la lengua, pues cada uno posee algún potencial de focalidad, aunque heterogéneo en número y jerarquía de acuerdo con el tipo de lengua que se trate.

Los recursos focales son de naturaleza fónica (por ejemplo, acentuación contextual), morfológica (por ejemplo, afijos de intensidad), léxica (por ejemplo, adverbios focales) y sintáctica (por ejemplo, oraciones copulativas enfáticas). Un buen número de especialistas (Martínez, 1999; Van Valin y LaPolla, 1997) coincide en que los medios fónicos poseen plena cobertura translingüística, de ahí que la posibilidad de diferenciar unas lenguas de otras pase más por establecer el lugar que ocupan en el sistema los recursos desarrollados en los restantes niveles lingüísticos.

La tesis anterior no supone que la prominencia prosódica tenga jerarquía universal. En efecto, su importancia en el conjunto de mecanismos focales varía de tipo a tipo e incluso de lengua en lengua cuando estas pertenecen a la misma tipología. Por ejemplo, español e inglés pueden ser contrapuestos a partir de su flexibilidad para linearizar y acentuar (Erteschik-Shir 2007), respectivamente. En español, los recursos de base sintáctica disponen de mayor amplitud funcional, en tanto que lo propio ocurre en inglés con el componente acentual.

No sorprende, entonces, que la lengua española haya desarrollado un inventario amplio de recursos sintácticos de focalidad, donde, además de las oraciones copulativas enfáticas, se encuentran las también copulativas oraciones ecuandicionales (Gutiérrez, 1997) y el orden de constituyentes, en el cual operan mecanismos como la dislocación y la pasivización analítica que, a diferencia de los anteriores, poseen más de una interpretación informativa.

Se desprende de los párrafos finales que las oraciones del estudio se inscriben en un potencial de realización y, por ello, su naturaleza y funcionamiento deben estar determinados por atributos comunes o sistémicos, entre ellos la capacidad de realzar, y por rasgos diferenciadores, más allá de la fisonomía sintáctica donde la singularidad es obvia. Sobre todo por esto último, nuestro esfuerzo principal estará dirigido a establecer el papel del factor acústico y su interrelación con el componente informativo de las construcciones ecuacionales.

En la NGLE (2009) estas construcciones focales (3) están situadas entre las oraciones copulativas enfáticas, junto a las copulativas con que galicado (4) y las copulativas enfáticas condicionales (5):

(3) Quien popularizó los documentales científicos es [Carl Sagan] FOCO

(4) Fue [Carl Sagan] que popularizó los documenFOCO

tales científicos

(5) Si alguien popularizó los documentales científicos es [Carl Sagan] FOCO

A diferencia de las enfáticas galicadas y condicionales, las oraciones ecuacionales Ilevan una oración de relativo, cuya palabra relativa (pronombre o adverbio) concierta referencial y formalmente (cuando es posible) con la magnitud focal. De lo anterior se sigue que tanto el que galicado como el si condicional no son unidades relativas (sino conjunciones subordinantes) y por ello la oración subordinada no incluye un elemento de correferencialidad. Por otra parte, las posibilidades lineares son muy limitadas en las focales galicadas e inexistentes en las condicionales, que presentan un trazado inicial fijo.

Por el contrario, las focales ecuacionales 
(también etiquetadas con generalizaciones como hendidas, escindidas, construcciones con grieta, construcciones de relieve, fórmulas perifrásticas de relativo) presentan una flexibilidad linear que las caracteriza con diferencia:

(3’) Es [Carl Sagan] quien popularizó los documen-
Foco tales científicos

(3”) [Carl Sagan] es quien popularizó los documentales científicos

La noción de flexibilidad se usa aquí en sentido diferente al de libertad distribucional, si bien tal distinción parece innecesaria en un análisis de raigambre funcional. Aun cuando la oración (3) y sus respectivas paráfrasis comparten proposición y constituyentes, difieren en su estructura informativa, lo cual obliga a interpretarlas como oraciones autónomas, sobre la base de la linearización de sus constituyentes centrales (verbo ser, oración relativa, magnitud focal) y la clase focal activada (contrastivo o neutro). Alineación y tipo focal deben conceptualizarse en el sentido más funcional posible, pues los factores asociados a la fisonomía lingüística e informativa de las oraciones enfatizadas ( $y$, por cierto, de cualquier oración) trascienden ambos planos o, mejor quizás, subyacen a ellos. Pensemos en la incidencia de la memoria de trabajo y de la capacidad atencional en la producción y comprensión del lenguaje.

De vuelta en los ejemplos, el enunciado (3') es una oración (copulativa enfática/ecuacional) hendida, singularizada por la posición interior del foco y la función contrastiva del mismo. La hendida es la variedad prototípica del grupo (de ahí que su nombre sea la etiqueta común de la clase) por su jerarquía cuantitativa, pero sobre todo por su capacidad para expresar en grado óptimo las propiedades centrales del conjunto. De hecho, es la única que solo posee interpretación focal.

Por su parte, (3) y (3") ilustran una oración ecuacional pseudohendida y pseudohendida inversa, respectivamente. Ambas pueden tener una lectura atributiva identificativa $y$, por ende, no focal en el sentido de foco adoptado en el presente trabajo (segmento en relieve). La posición del segmento foco determina que la primera esté más especializada en el relieve de información dada y la segunda, en el realce de contenido nuevo, basado en el hecho de que un segmento focal contrastivo (característico de la hendida) representa la reelaboración de una información anterior (la cual puede resultar anulada o corregida por el contenido ponderado), frente a la ecuacional inversa, cuyo foco preferentemente neutro no está ligado a un contexto discursivo inmediato. El potencial fórico explicaría que la variedad pseudohendida se imponga en productividad a la hendida cuando la focalidad está asociada a una estrategia de coindización; algo muy parecido ocurre con los constituyentes topicales. Puede añadirse la posibilidad de que esta construcción ecuacional contribuya a regular la progresión informativa del enunciado (desde lo más conocido a lo más nuevo), caso en que el foco pseudohendido permitiría mayor capacidad de individuación

Las propiedades no formales que se pueden alegar en torno a las diferencias específicas de la clase ecuacional son bastante intuitivas, debido a los pocos estudios que han abordado el fenómeno. Es muy posible que los trabajos pioneros de Sedano para el español (1990) sigan contando aún entre las referencias más concretas. Además, debemos a la autora un análisis comparativo con otras lenguas romances (1995, 1996), el cual resulta muy valioso para sistematizar los rasgos críticos de estas construcciones de relieve.

La noción de paráfrasis empleada para referirnos a los diferentes casos de copulativas enfáticas (y recurriremos al mismo concepto para denominar la equivalente no focal) conlleva la adhesión a dos postulados funcionales de enorme trascendencia teórica y metodológica, a saber: Ia no distinción entre una estructura profunda y otra superficial y el rechazo a la existencia 
de procedimientos transformativos. El siguiente ejemplo será muy útil para explicar ambas asunciones:

(6) Carl Sagan popularizó los documentales científicos

Podría pensarse, sobre todo bajo la influencia del generativo clásico (teoría estándar), que esta oración corresponde a una oración de base de la cual derivaron las ecuacionales examinadas con anterioridad. Sin embargo, esta interpretación debe descartarse, pues los enunciados adoptan la fisonomía más pertinente a la intención y al contexto comunicativo del cual son parte. Por lo demás y pensando en el generativismo actual, la posibilidad de que existan operaciones transformacionales o algo similar es irreconciliable con la simpleza de diseño que requiere el funcionamiento de la cognición, dentro de la cual el lenguaje es un componente más que debe interactuar con otros, entre ellos, la memoria operativa y el sistema perceptual-articulatorio.

Pero la declaración anterior no es gratuita; implica algunos costos teóricos. El primero es que se opone a la intuición común de que buena parte de la actividad lingüística descansa en la capacidad de desplazar constituyentes para formar oraciones. Lo segundo es que por imperativo de consistencia obliga a prescindir de explicaciones basadas en la noción de movimiento, aun cuando puedan tener el potencial necesario para explorar la interficie de los niveles lingüísticos.

Muestra de lo anterior es la imposibilidad de conciliar nuestra interpretación con el valioso trabajo de Rodríguez (2005). La autora plantea la existencia de movimientos de focalización y defocalización destinados a llevar y sacar constituyentes de las zonas de dominio del acento contextual (contrastivo y neutro). Esta tesis incluye una segunda asunción que vincula causalmente linearización y acentuación oracional. El valor de la hipótesis de Rodríguez bien merecería el esfuerzo de acercar posiciones, armonizando, por ejemplo, la noción de movimiento prosódi- co con la de locación prosódica (Pinuer y Oteíza, 2012a), a pesar del prurito epistemológico que desencadenan soluciones como esta.

Dada la preponderancia del constituyente focal en la interacción comunicativa, específicamente para el enriquecimiento informativo del destinatario, los segmentos focalizables tienen referencialidad extralingüística y, por ello, es discutible que entidades morfémicas y gramaticales (artículos, preposiciones, conjunciones) puedan ser objeto de focalización, aunque sí de énfasis en el marco de un concepto más amplio de focalidad como la adoptada en este trabajo. En concreto, oraciones, sintagmas y palabras de referencialidad o individuación son susceptibles de aparecer focalizados o, dicho desde otra perspectiva, presentan la capacidad de codificar epicentros informativos.

Así como es funcionalmente válido sostener que cualquier decurso lingüístico es una entidad comunicativa, resulta igual de admisible señalar que las oraciones ecuacionales (y, en rigor, toda construcción focal) están especialmente volcadas a la función informativa, hasta el punto de sacrificar regulaciones formales si con ello se cumple el propósito de realzar:

\section{(7) ??Lo que Carl Sagan fue [es un pionero] FOCO}

En esta oración, además de la comúnmente evitable contigüidad de ser (y de cualquier otro verbo), se aprecia la descoordinación temporal entre sus dos manifestaciones flexivas, la cual minora el efecto de la duplicación y proporciona un cierto grado de aceptabilidad que se impone a la gramaticalidad como elemento de legitimación estructural. La flexibilidad temporal que muestra el verbo ecuacional es uno de los varios rasgos idiosincrásicos de la construcción que la gramática académica (2009) explica mediante la noción de efecto de contagio.

\subsection{El factor acústico}

La preponderancia informativa del foco tiene un correlato acústico equivalente, pues 
"cuando una palabra es el foco de la oración, el tono sube durante la sílaba acentuada y llega a su altura máxima dentro de esa misma sílaba" (Face, 2002: 32). Si ya destacamos que todas las lenguas manifiestan función focal, de la misma forma debe subrayarse ahora que el medio fónico es en todas un recurso común de focalidad, aunque con diversa cobertura, como podrá verificarse enseguida.

En inglés, la prominencia prosódica es el medio más importante para producir focalidad, hecho concordante con el valor que autores como Halliday (2005: 192) atribuyen a la entonación en la organización informativa de sus enunciados: "In English, information structure is expressed by intonation. Connected speech takes the form of an unbroken succession of distinctive pitch contours, or tone groups; each tone group represents what the speaker decides to make into one unit of information".

Caso contrario es el del español, pues se ha establecido que en esta lengua el plano prosódico cumple un papel menor en la codificación de foco y no así el nivel sintáctico al cual se asigna la máxima rentabilidad instanciadora, destacando el orden de constituyentes (OC), que Martínez (1999: 4) distingue como el medio de mayor cobertura: "En español es la variación OC el mecanismo que señala principalmente esta función". Con una mirada tipológica, esta diferencia representa un contrapeso, tal como lo ha destacado la misma autora (1999: 299): "Se compensa así una estructura sintáctica relativamente rígida del inglés con la flexibilidad de la posición de su AN y la mayor rigidez de los patrones prosódicos en español con su flexibilidad sintáctica”.

No obstante, la jerarquía focal del OC ha sido verificada (y validada) en general para oraciones declarativas, cuya linearización canónica, además de no poder trasvolarse a los restantes modos oracionales, depende del predicado verbal, y buen ejemplo de ello es la diferencia linear de sujeto (S) y verbo (V) en la predicación inergativa (8) y ergativa (9):
(8) Carl Sagan nació en Nueva York [S-V]

(9) Aparecieron estudios inéditos de Carl Sagan [V-S]

Por otra parte, se sabe que ciertos tipos de focos se distinguen en español prosódicamente, materia en la cual Silva-Corvalán (2001: 176) ha señalado que "la diferencia estructural entre los Os [objetos] focales y los contrarios a lo esperado es establecida por la entonación". Precisa que en el caso de los complementos focales, "el O[bjeto] preverbal constituye el único punto de prominencia y el descenso del tono no es gradual sino brusco" (ibíd.). Face (2002: 44) pone también en duda la separación radical entre prosodia y orden de constituyentes señalada en un comienzo: "No es totalmente válida puesto que hay varios estudios sobre las maneras en que la entonación marca el foco en lenguas como el español y el italiano...".

Hacemos notar que los parámetros prosódicos (entonación, duración, energía, pausa), a diferencia de las magnitudes sintácticas e informativas, son distintivos en relación con la naturaleza de su manifestación, pues siempre están presentes (Lucci, 1983).

En los estudios de relieve prosódico, la unidad básica de análisis es el grupo fónico, definido como un bloque fonológico que representa una división discursiva de la cadena lingüística, donde la pausa es el factor clave. La importancia asignada al grupo fónico se refuerza de cierto modo con el hecho, ya señalado por Halliday, de que la unidad cumple una función importante en la estructura informativa: "El grupo fónico no es sólo una unidad fonológica, sino que expresa además una unidad de información, de manera que el hablante distribuye su mensaje en secuencias portadoras de información" (Martínez, 1999: 23-24).

Por cierto que la subdeterminación pragmática de las unidades fónicas se extiende al resto del sistema lingüístico y ejemplo de ello es la cláusula: "With its organization as a message, 
the clause is also organized as an interactive event involving speaker, or writer, and audience" (Halliday y Matthiessen, 2004: 106).

En cuanto magnitud informativa, el grupo fónico tiene en el acento de intensidad (AN) uno de sus parámetros centrales, debido a que se comporta como el rasgo más prominente y sistemático de la expresión focal. El AN identifica la porción de enunciado con mayor saliencia informativa, tal como lo hacen otros medios gramaticales y léxicos. Según Face (2002: 32), entre los formantes del AN, el tono es el factor clave para la delimitación prosódica del foco, pues lo marca "de forma regular". Otros parámetros, como la duración silábica y la intensidad, también son parte del correlato acústico de la focalización, pero de un modo menos distintivo y, sobre todo, menos sistemático.

En estudios realizados en el español dominicano, Sosa (2003: 406) verificó, en relación al carácter saliente del foco, que "la representación $H^{*}$ en posición prenuclear remite a énfasis o foco...". Resultados similares se reportan en el español de Madrid (Face, 2002) y México (Kim y Avelino, 2003). En el caso del español de Chile, investigaciones desarrolladas por Cid y Maluenda (2005: 54) comprobaron una incidencia significativa del alargamiento: "Como reforzador del foco, el alargamiento segmental se manifiesta prosódicamente con un descenso tonal que va desde el nivel superior del rango tonal al nivel más bajo del mismo".

El examen de la materialización acústica de la focalidad, desde otra perspectiva, debe deslindar entre la unidad resaltada y el entorno segmental. Para Face (2002), este es un hecho metodológico relevante, pues obliga a distinguir entre tono local y tono global. Específicamente en materia de tono global, es poco lo que se sabe aún acerca de fenómenos prosódicos pre-y posfocales, que podrían actuar como indicios de anticipación y culminación del proceso. Otro aspecto en el que también hay un conocimiento reducido es la realización de focos simultáneos o paralelos, focalidad mixta en nuestro concepto, algo acústicamente posible "a condición de que el enunciado se divida en varios grupos melódicos” (Martín Butragueño, 2005: 4).

La interrelación entre grupo fónico y AN es básica en la distinción entre foco amplio y foco restringido. "En el primer caso, todo el grupo fónico está en foco, mientras que en el segundo, sólo uno de los constituyentes gramaticales que forman parte del grupo fónico entra dentro del foco", aclara Martínez (1999: 25). En materia de foco contrastivo, este es singularizado por no admitir comúnmente el AN en la última palabra léxica del grupo fónico. Recordemos que, en general, el "enunciado que contiene un foco contrastivo expresa la idea de que el hablante tiene en la mente una serie de posibles candidatos a los que asociar una determinada predicación; entre estos candidatos, aquél enfatizado ha sido seleccionado por exclusión del resto" (BertucceIli, 1996: 156).

Silva-Corvalán (2001: 174-175) ha descrito la existencia de Os preverbales (dislocados) sobre la base de un contorno fonológico contraesperado, que describe así: "Está compuesto de un tono inicial alto y de una caída rápida de tono final [...] seguido de un tono bajo y sin prominencia que se mantiene hasta el final de la oración". Los trabajos de Kim y Avelino (2003: 368-369) confirman el valor del parámetro duración, pero llegan a un resultado diferente en lo que a entonación se refiere: "Duration plays a significant role in distinguishing focus type". Además, obtuvieron evidencia suficiente para proponer que "there is not correlation between focus type and peak alignment" $\mathrm{y}$ "the shifting of $\mathrm{H}^{*}$ peak is not a property related to a specific focus type” (ibíd.).

A objeto de no sobredimensionar los hallazgos contrarios sobre el grado incidental del factor prosódico, conviene tener presente que su estudio es aún preliminar en comparación con lo que sucede en los restantes niveles de la lengua. Además, la investigación acústica del fenómeno está mucho menos desarrollada en español que 
en otras lenguas, como advierte Ortiz-Lira (2000: 11): "La situación es particularmente deficitaria en el área de acentuación contextual (también llamada oracional, de frase, sintáctica o postléxica en la literatura especializada) aplicada al habla espontánea, a diferencia de lo que ocurre en las lenguas germánicas, especialmente en el inglés".

Como se puede apreciar, los desafíos para la investigación del componente suprasegmental son mayores y no solo en su volumen, sino también en el ámbito metodológico, a fin de asegurar niveles aceptables de confiabilidad, para lo cual es decisivo filtrar las observaciones impresionísticas que han conspirado en la calidad de Ios hallazgos. Para Kim y Avelino (2003: 360), esta es una debilidad presente en muchos trabajos: "They limit their description to an impressionistic observation of the intonational properties of different focus types without any analyses supporting their claims".

La necesidad de extremar el rigor metodológico se acentúa al tener en cuenta que la relación entre funciones informativas y prosodia no es biunívoca o mecánica. Según Martín Butragueño (2005: 21), "de la misma manera que no todo acento enfático sobre un constituyente antepuesto es un foco, no todo foco antepuesto recibe una lectura prosódica diferente a la de dislocación sintáctica”. Sobre el mismo punto, Kim y Avelino (2003: 361) plantean que "there has not been any specific phonetic or intonational study addressing the interaction between word order variation and focus in Spanish".

Por último, se puede agregar junto con Martín Butragueño (2005: 23) que "son muchas las desavenencias entre la estructura sintáctico discursiva y la estructura prosódica”. Sin embargo, la falta de simetría que se denuncia en la cita no debe interpretarse en un sentido muy literal, pues debe tenerse presente que todo enunciado se construye para satisfacer requerimientos interactivos específicos, de modo que "las variaciones no son arbitrarias ni aleatorias, sino que forman parte de los objetivos comunicativos de los hablantes, y al serlo, las diferencias melódicas tendrían implicaciones fonológicas" (Sosa, 2003: 420).

\section{Metodología del estudio 3.1. Objetivos}

- Caracterizar la fisonomía acústica de las estructuras ecuacionales

- Determinar diferencias acústicas entre las variedades ecuacionales.

- Establecer correlatos acústicos en las propiedades lexicogramaticales e informativas prominentes de las construcciones ecuacionales.

\subsection{Obtención de la muestra}

Se conformó un corpus de 150 minutos de habla espontánea producida por sujetos masculinos adultos en programas de conversación y entrevista de radio y televisión chilenas. El material fue almacenado por medio del editor Audacity y luego sometido a una fase de revisión perceptual para seleccionar y editar los enunciados correspondientes a oraciones copulativas enfáticas de acuerdo con las propiedades informativas y sintácticas descritas para la estructura. La muestra final de la investigación quedó en 21 oraciones, equivalentes a 10 minutos de grabación, distribuidas en 10 hendidas $(\mathrm{H}), 7$ pseudohendidas (PSH) y 4 pseudohendidas inversas (PSHI).

\subsection{Protocolo de análisis prosódico}

El estudio acústico se desarrolló a través del procedimiento de análisis melódico propuesto por Cantero (2002) y reformulado luego en Cantero y Font (2009). El modelo analítico se basa en el concepto de jerarquía fónica, según el cual el habla está formada por unidades fónicas trabadas y jerarquizadas: la sílaba, la palabra fónica (o grupo rítmico) y el grupo fónico. La unidad de análisis de la melodía es el segmento tonal, entendido como el valor tonal del núcleo silábico, normalmente una vocal. Por medio del programa de análisis del habla Praat, se mide y regis- 
tra el valor absoluto en $\mathrm{Hz}$ de cada una de las vocales del enunciado. Con la obtención de los valores de Fo por cada vocal, se logra caracterizar acústicamente los elementos estructurales del contorno: el anacrusis, que es la parte del trazado melódico anterior a la primera vocal tónica del contorno llamada primera cima del contorno entonativo; el cuerpo, que comprende la primera cima hasta la última vocal tónica del contorno o núcleo; y la inflexión final, que permite definir la melodía del contorno y establecer los patrones melódicos característicos de cada tonema para la muestra total de enunciados ecuacionales.

La siguiente figura muestra el esquema de la estructura del contorno entonativo y rasgos melódicos (Cantero, 2002: 161).

\section{FIGURA 1}

Estructura del contorno entonativo y rasgos melódicos

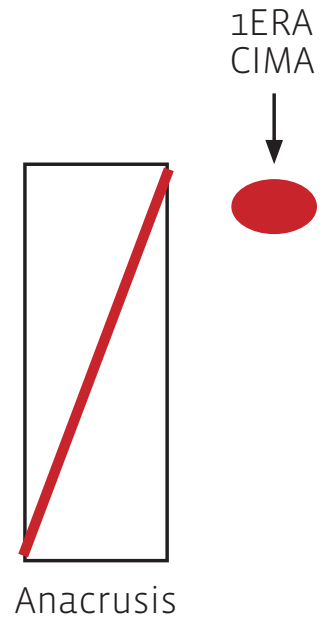

como se muestra en el gráfico 2: "proble" en vez de "pro-ble-ma".

Con el fin de complementar la información obtenida con el protocolo diseñado por Cantero y Font (2009), se consideraron otros factores prosódicos como la pausa y la duración.

\section{Presentación y discusión de resultados}

En primer lugar, se analizó toda la muestra con el objetivo de establecer tendencias a nivel de fisonomía acústica general. En segundo lugar, se desarrolló el estudio acústico detallado de dos enunciados prototípicos de cada variedad ecuacional, con los respectivos gráficos; esto nos permitió comparar sus trazados melódicos y

Anacrusis

cuerpo
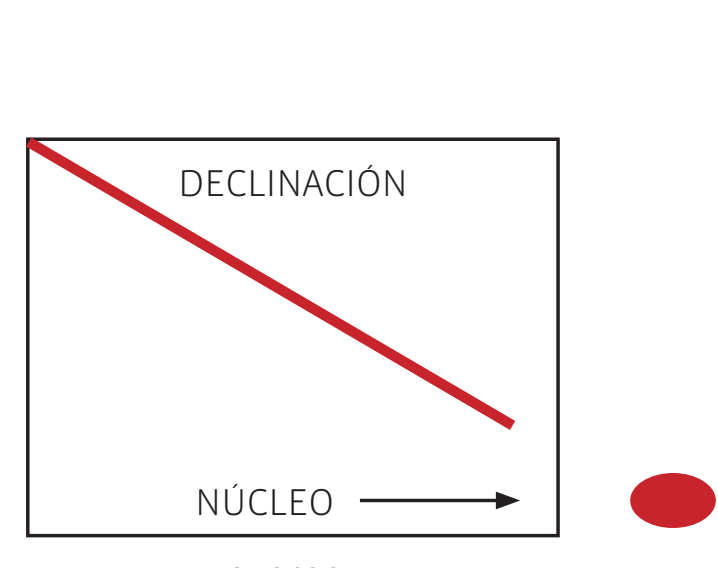

inflexión final

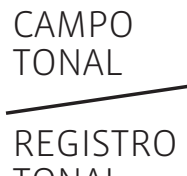

TONAL
En cuanto a las anotaciones de los valores en $\mathrm{Hz}$ por cada vocal, se registraron dos o tres valores para aquellas vocales tónicas que presentaban inflexiones tonales internas o circunflejas. En estos casos, se repitió la sílaba con letras mayúsculas, lo cual se puede observar en el gráfico 1. Los enunciados ecuacionales analizados aquí corresponden a elocuciones producidas por los hablantes a mucha velocidad; por ello, en algunos casos, las palabras no aparecen separadas por cada sílaba, sino en agrupaciones silábicas, determinar patrones específicos por estructura. Finalmente, se describieron dos casos de oraciones ecuacionales que presentaron alguna particularidad en relación al conjunto de la muestra.

\subsection{Resultados generales}

En términos generales, las copulativas hendidas presentan una correlación acústica más regular que las variedades pseudohendida y pseudohendida inversa. El primer constituyente en foco es emitido con un marcado ascenso 
tonal, produciéndose en la mayoría de los casos la cima tonal temprana señalada por Face (2001, 2002). El cuerpo de la curva se manifiesta con un descenso brusco del tono, para luego caer paulatinamente hasta la zona prenuclear. La inflexión final característica de estas construcciones es un descenso tonal simple o circunflejo. Solo dos casos rompen esta tendencia: las hendidas $\mathrm{HO}_{4}$ y Ho6.

En cuanto a las estructuras pseudohendidas, cinco de las emisiones analizadas se comportan como un enunciado en foco amplio, es decir, la mayor prominencia acústica se da en los constituyentes finales de la curva. El acento nuclear puede realizarse con énfasis acústico o sin él. Por otra parte, se verifican hallazgos excepcionales en SHol, cuyo acento enfático recae sobre un constituyente de la cláusula relativa, y en SHo7, que presenta un énfasis acústico al inicio de la emisión, similar al de una estructura hendida.

Finalmente, las pseudohendidas inversas se comportan acústicamente de manera similar a lo observado en las ecuacionales hendidas, es decir, la cima tonal se da alineada en el constituyente en foco al inicio de la emisión, para luego descender el tono en el cuerpo de la curva hasta la zona prenuclear. Por último, el tonema presenta un descenso simple o circunflejo.

\subsection{Análisis acústico}

Los resultados que se exponen a continuación van acompañados de un gráfico y una tabla que ilustra el trazado prototípico con sus respectivos valores de Fo (Hz), porcentaje (\%) y curva estándar (CE)4. Los comentarios aparecen organizados de acuerdo a los elementos estructurales del contorno entonativo: anacrusis, cuerpo e inflexión final. Como una forma de aportar a los trabajos perceptivos sobre foco, se han agregado valores en semitono (ST) en la porción de la curva más pertinente. Los corchetes mostrarán el segmento focalizado y la mayúscula identificará el constituyente acentuado enfáticamente.

\subsubsection{Hendida 01}

\section{GRÁFICO Y TABLA 1}

Representación melódica de la emisión:

"Y es [ALLí] donde podrían estar las mayores dudas"

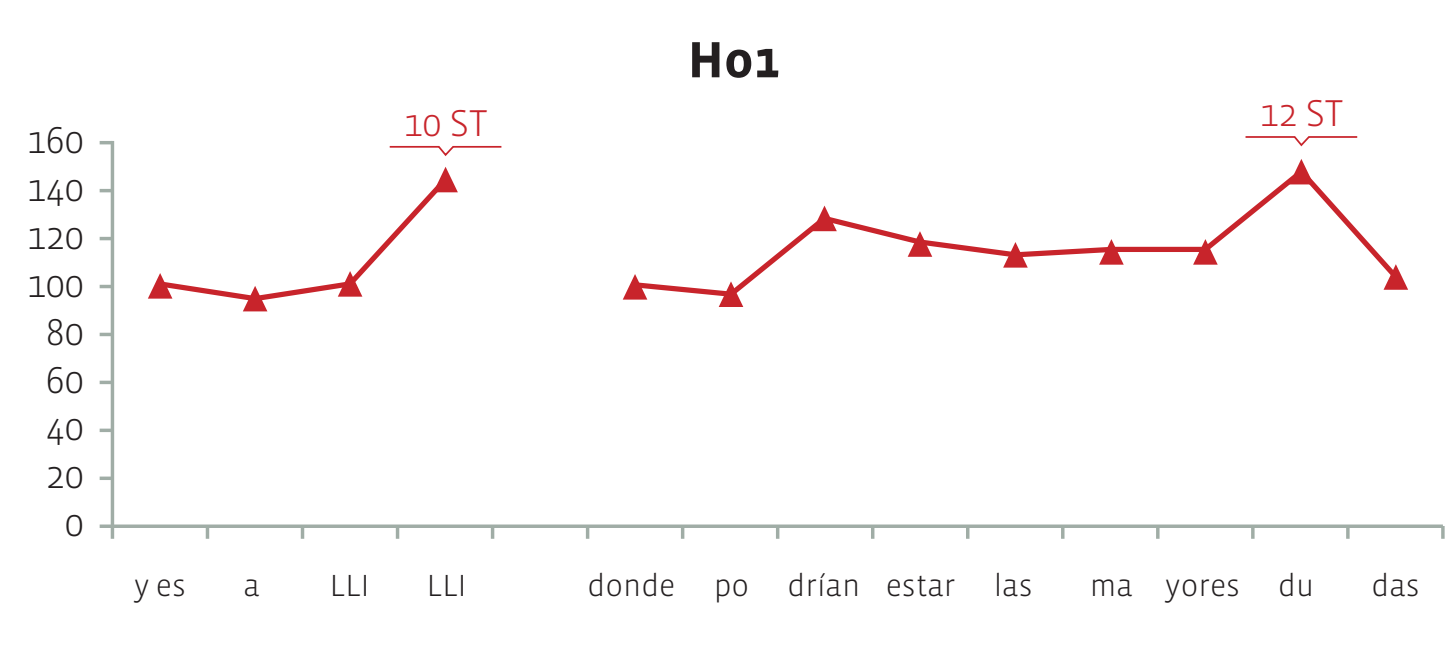

4 Por razones de espacio, no se han incluido en este artículo los gráficos y tablas de los 21 enunciados, los cuales están disponibles en: http://www2.udec.cl/ heperez/fonetica/archivo/graficos-hendidas.pdf. 


\begin{tabular}{c|c|c|c|c|c|c|c|c|c|c|c|c|c|c} 
Ho1 & y es & a & LLI & LLI & & donde & po & drían & estar & las & ma & yores & du & das \\
\hline Hz & 195 & 185 & 196 & 282 & Hz & 156 & 151 & 198 & 179 & 170 & 172 & 173 & 230 & 129 \\
\hline$\%$ & 100 & -5 & 6 & 44 & $\%$ & -45 & -3 & 31 & -10 & -5 & 1 & 1 & 33 & -44 \\
\hline CE & 100 & 95 & 101 & 145 & CE & 100 & 97 & 128 & 118 & 113 & 114 & 115 & 148 & 104
\end{tabular}

Ho1 presenta una subdivisión del grupo melódico a través de nuevos tonos de juntura, coincidiendo con lo observado por Martín Butragueño (2005: 119) para el foco prosódico. En la primera parte de la emisión, tanto el anacrusis como el cuerpo de la curva muestran pocas variaciones tonales perceptibles antes de llegar al constituyente focal [ALLÍ]. En este componente, se produce la cima tonal con alineación de la sílaba tónica. Posteriormente, el sujeto de la emisión realiza un tono de frontera que se traduce en una pausa evidente de 1.190 ms. En el segundo grupo melódico, el anacrusis y el cuerpo de la curva se mantienen con pocas variaciones tona- les hasta llegar a la última inflexión. En esta porción final de la curva, la cima tonal se alinea con la sílaba tónica (DUdas) en un ascenso de 51\%, para luego descender 50\% en la sílaba postónica, lo que se traduce en una inflexión final circunfleja. En relación con los valores en semitonos, la prominencia tonal del primer grupo melódico registra un ascenso de 10ST en comparación con el resto de la curva de esta primera porción emitida. En el segundo grupo melódico, la inflexión circunfleja final registra un ascenso y descenso del tono en 12ST.

\subsubsection{Hendida 03}

\section{GRÁFICO Y TABLA 2}

Representación melódica de la emisión:

"Es [ÉL] el que tiene que resolver el problema"

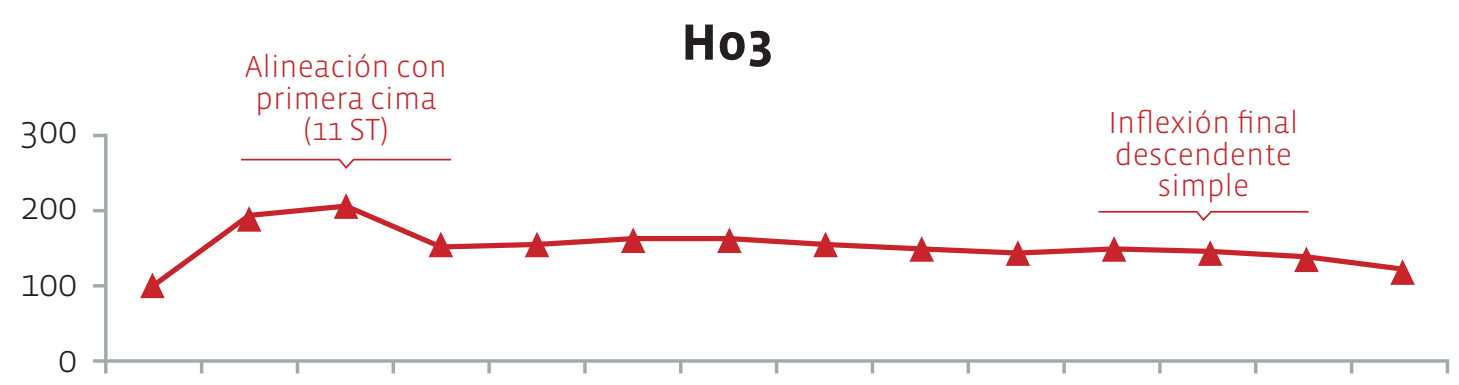

es EL EL el que tie ne que re sol ver el proble ma

\begin{tabular}{c|c|c|c|c|c|c|c|c|c|c|c|c|c|c} 
Ho3 & es & EL & EL & el & que & tie & ne & que & re & sol & ver & el & proble & ma \\
\hline Hz & 125 & 241 & 276 & 134 & 135 & 144 & 142 & 131 & 127 & 120 & 126 & 119 & 111 & 95 \\
\hline$\%$ & 100 & 93 & 15 & -51 & 1 & 1 & -2 & -7 & -3 & -6 & 5 & -6 & -7 & -14 \\
\hline CE & 100 & 193 & 207 & 156 & 156 & 163 & 161 & 154 & 151 & 146 & 151 & 145 & 138 & 124
\end{tabular}

En relación con el anacrusis (gráfico 2), se observa un ascenso del tono hasta llegar a la cima tonal con alineación de la sílaba tónica
$(E ́ l)$, similar a lo que ocurre en el primer grupo

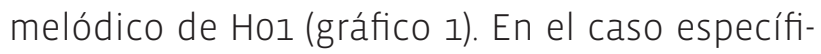
co de $\mathrm{Ho3}$, el tono sube un 93\%, lo que equivale 
a IIST. La emisión continúa con el cuerpo de la curva melódica, registrando un descenso tonal muy marcado de más de $12 \mathrm{ST}$, lo que se revela en el gráfico como una prominencia en la zona del constituyente focal. Luego, esta porción del trazado continúa con un descenso paulatino con pocas variaciones tonales hasta llegar a una inflexión final simple. Por último, se puede indicar que la sílaba en foco fue notoriamente más larga en comparación con los otros constituyentes del enunciado, a excepción del último. Lo anterior confirma lo establecido por Lucci (1993) en relación a la variedad de recursos prosódicos para marcar la información jerarquizada.

\subsubsection{Pseudohendida SHO2}

\section{GRÁFICO Y TABLA 3}

Representación melódica de la emisión:

"Lo que dije en esa junta es [que teníamos muchos RECURSOS, que estamos en un gobierno

normal y había que jerarquizar y priorizar]"

\section{SHO2}

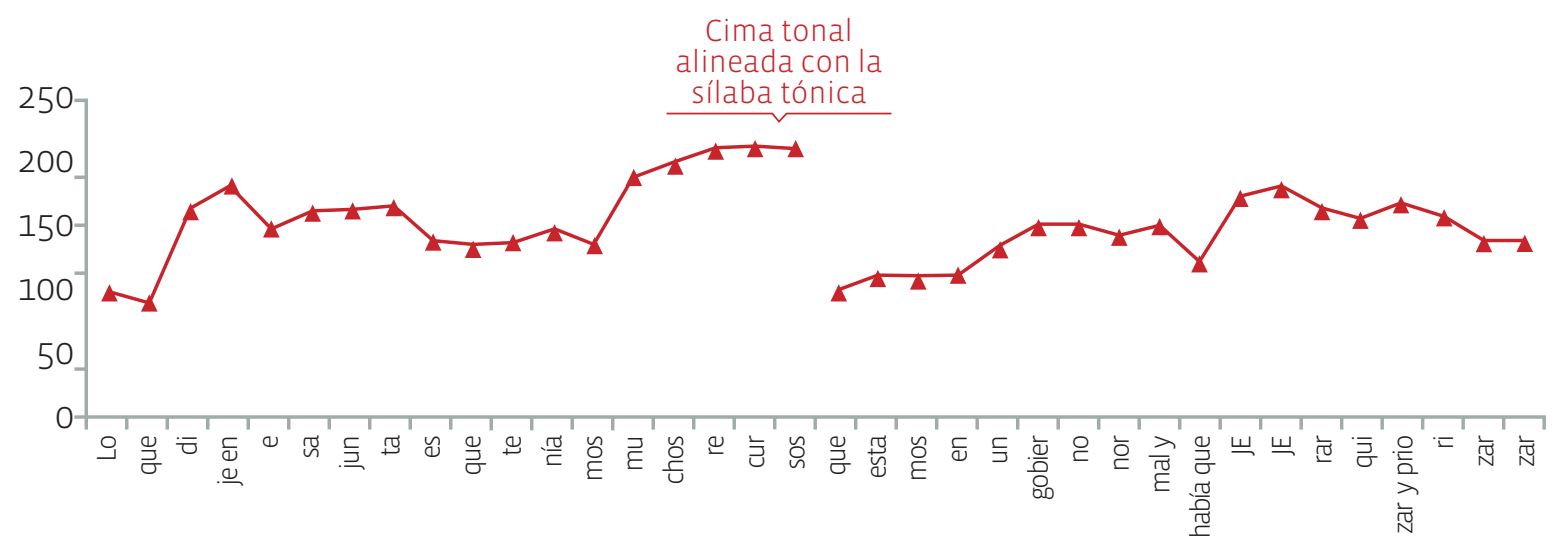

\begin{tabular}{c|c|c|c|c|c|c|c|c|c|c|c|c|c|c|} 
SHo2 & Lo & que & di & je en & e & sa & jun & ta & es & que & te & nía & mos & mu \\
\hline $\mathbf{H z}$ & 97 & 89 & 154 & 182 & 124 & 137 & 140 & 144 & 107 & 101 & 104 & 114 & 102 & 156 \\
\hline$\%$ & 100 & -8 & 72 & 18 & -32 & 11 & 2 & 3 & -26 & -6 & 3 & 10 & -10 & 52 \\
\hline CE & 100 & 92 & 164 & 182 & 151 & 161 & 163 & 166 & 140 & 134 & 137 & 147 & 137 & 189
\end{tabular}

\begin{tabular}{|c|c|c|c|c|c|c|c|c|c|c|c|c|c|} 
chos & re & cur & sos & SHoz & que & esta & mos & en & un & gobier & no & nor & mal y \\
\hline 172 & 190 & 195 & 194 & Hz & 92 & 103 & 101 & 104 & 126 & 147 & 147 & 135 & 145 \\
\hline 11 & 11 & 2 & 0 & $\%$ & 100 & 11 & -1 & 2 & 22 & 16 & 0 & -8 & 7 \\
\hline 200 & 210 & 213 & 212 & CE & 100 & 111 & 110 & 112 & 134 & 151 & 150 & 143 & 150
\end{tabular}

\begin{tabular}{|c|c|c|c|c|c|c|c|c} 
habia que & JE & JE & rar & qui & zary prio & ri & zar & zar \\
\hline 106 & 158 & 172 & 143 & 131 & 146 & 134 & 106 & 106 \\
\hline-27 & 50 & 9 & -17 & -9 & 12 & -9 & -21 & 0 \\
\hline 123 & 172 & 181 & 164 & 156 & 168 & 159 & 138 & 138
\end{tabular}


Esta construcción registra una subdivisión del grupo melódico, como ocurre en Hol (ver gráfico y tabla 1). La emisión de SHoz incluye un breve anacrusis en "lo que", con desplazamiento de la cima tonal hacia la sílaba postónica (diJE), para luego manifestar un descenso de 31\% (7ST). En el cuerpo de la curva, se producen ascensos y descensos poco significativos hasta un descenso marcado de 26\% (5ST), previo a la cláusula de relativo donde se encuentra la magnitud enfatizada. A continuación, se detecta un ascenso escalonado de $52 \%(7 \mathrm{ST}), 11 \%(1,6 \mathrm{ST})$ y $11 \%(1,7 \mathrm{ST})$ en los constituyentes muchos reCURsos. Además, la cima tonal se ubica en la sílaba tónica de esta última palabra, culminando el trazado con un tonema ascendente. Entre el primer y segundo contorno, se produce un tono de frontera que se traduce en una pausa evidente de $0.63 \mathrm{~ms}$. En el segundo grupo melódico, el anacrusis y cuerpo de la curva se materializa con ascensos y descensos tonales hasta la sílaba nuclear del constituyente jerarquizar, que alcanza una cima tonal de $172 \mathrm{~Hz}$, pero que no supera la altura tonal registrada en el núcleo del primer contorno melódico (195Hz). La inflexión final de este segundo grupo melódico se manifiesta con un descenso escalonado.

\subsubsection{Pseudohendida SH05}

\section{GRÃFICO Y TABLA 4}

Representación melódica de la emisión:

"Es que [este techo de 200 mil para el aporte previsional solidario se SUBA ojalá a 300 mil]”5

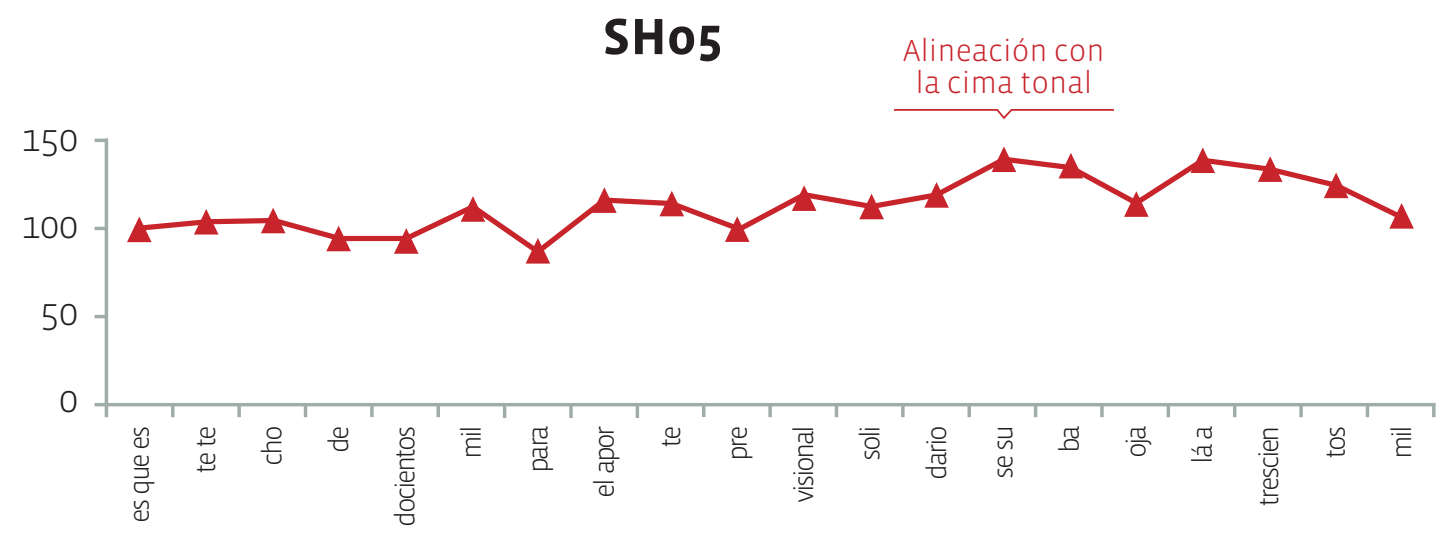

\begin{tabular}{c|c|c|c|c|c|c|c|c|c|c|c|} 
SHo5 & es que es & te te & cho & de & docientos & mil & para & el apor & te & pre & visional \\
\hline Hz & 133.3 & 138 & 141 & 125 & 123 & 146 & 111 & 143 & 140 & 120 & 142 \\
\hline$\%$ & 100 & 3 & 2 & -11 & -11 & 18 & -24 & 29 & -2 & -14 & 18 \\
\hline CE & 100 & 103 & 105 & 94 & 94 & 111 & 87 & 116 & 114 & 100 & 118
\end{tabular}

\begin{tabular}{|c|c|c|c|c|c|c|c|c} 
soli & dario & se su & ba & oja & lá a & trescien & tos & mil \\
\hline 133 & 143 & 172 & 165 & 132 & 164 & 154 & 141 & 116 \\
\hline-6 & 7 & 20 & -4 & -20 & 24 & -6 & -8 & -18 \\
\hline 112 & 120 & 140 & 136 & 115 & 140 & 134 & 125 & 107
\end{tabular}

5 En este enunciado, falta el constituyente relativo "lo que esperamos", el cual fue producido al margen del caso en estudio. 
En el gráfico y tabla 4 se puede comprobar que la emisión registra en general un trazado de ascensos y descensos tonales a lo largo de todo el enunciado. La primera cima se produce en el constituyente MIL $(145,9 \mathrm{~Hz})$ para dar paso al cuerpo de la curva con tonos altos y bajos que van desde $14 \%$ a $29 \%$. El tono más alto de la curva ocurre en el constituyente SUba $(172,2 \mathrm{~Hz})$, con alineación en sílaba tónica. La inflexión final es descendente simple, aun cuando se observa un ascenso y descenso leve posnuclear, pero que no logra registrar un valor de tono más alto que el observado en la sílaba nuclear. Si comparamos el descenso del tono desde la sílaba nuclear hasta la última emitida, se registra una diferencia de 7ST.

\subsubsection{Pseudohendida inversa SHIO2}

\section{GRÁFICO Y TABLA 5}

Representación melódica de la emisión:

"Y [ESO] es lo que me motiva"

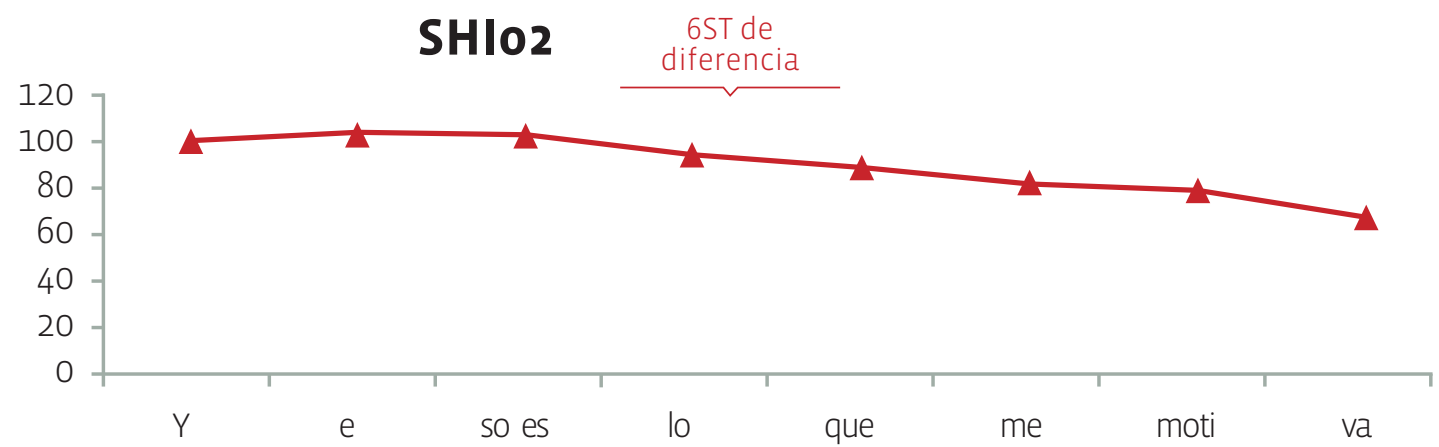

\begin{tabular}{c|c|c|c|c|c|c|c|c} 
SHI02 & $\mathbf{Y}$ & $\mathbf{e}$ & so es & lo & que & me & moti & va \\
\hline Hz & 118.8 & 123.4 & 122.6 & 111.1 & 105 & 97.6 & 94.8 & 84 \\
\hline$\%$ & 100 & 4 & -1 & -9 & -5 & -7 & -3 & -11 \\
\hline CE & 100 & 104 & 103 & 94 & 88 & 81 & 78 & 67
\end{tabular}

La pseudohendida SHIO2 se caracteriza acústicamente por tener valores más altos al inicio de la emisión para terminar en un descenso paulatino y sostenido con una inflexión final simple. Como ha sido la constante en las oraciones hendidas y pseudohendidas descritas hasta aquí, también en este tipo de estructura se observa una alineación del tono con la sílaba tónica del elemento en foco (ESo). La diferencia de tono registrada entre el inicio $(118.8 \mathrm{~Hz})$ de la curva y el final de ella $(84.1 \mathrm{~Hz})$ es de $6 \mathrm{ST}$.

\subsubsection{Pseudohendida inversa SHOO}




\section{GRÄFICO Y TABLA 6}

Representación melódica de la emisión:

"[AHÍ] es donde yo tengo problemas"

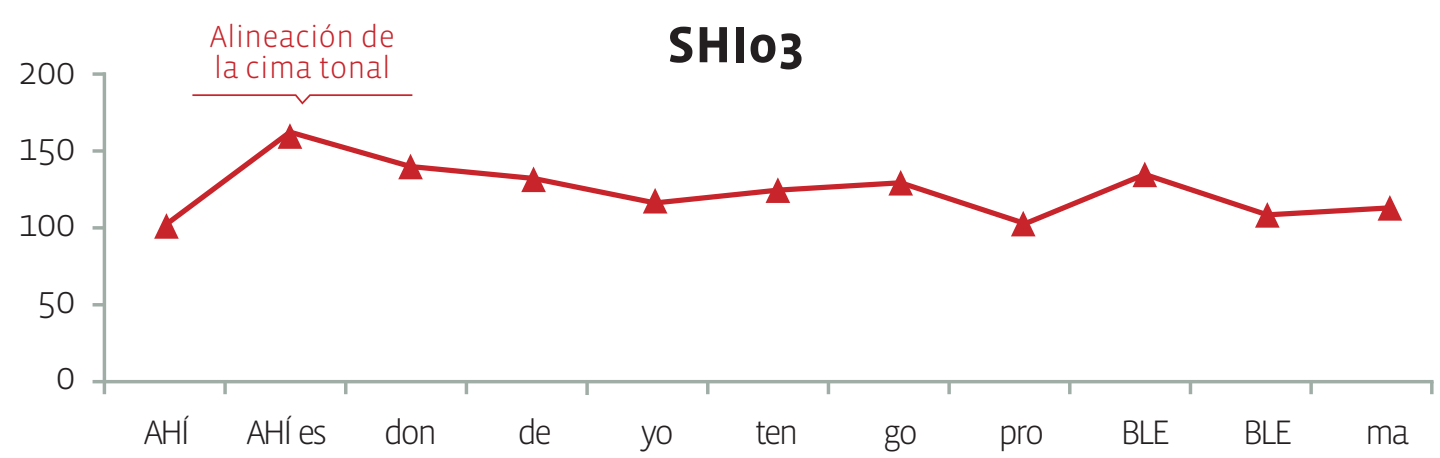

\begin{tabular}{c|c|c|c|c|c|c|c|c|c|c|c} 
SHI03 & AHİ & AHİ es & don & de & yo & ten & go & pro & BLE & BLE & ma \\
\hline Hz & 123.9 & 198.5 & 154.8 & 143.7 & 122.2 & 131.1 & 137.1 & 102.4 & 135 & 99.6 & 103.9 \\
\hline$\%$ & 100 & 60 & -22 & -7 & -15 & 7 & 4 & -25 & 32 & -26 & 4 \\
\hline CE & 100 & 160 & 138 & 131 & 116 & 124 & 103 & 103 & 134 & 108 & 113
\end{tabular}

El gráfico 6 evidencia que esta pseudohendida inversa tiene un comportamiento melódico similar a los descritos para las oraciones hendidas (gráficos 1 y 2). La prominencia acústica mayor se observa en el componente en foco (aHI), al principio de la curva. También se detecta un alargamiento notorio de la sílaba tónica y un ascenso de un 60\% por sobre la base del trazado. Al inicio del cuerpo de la curva, se realiza una inflexión tonal con un tono bajo $(154.8 \mathrm{~Hz})$ que sigue descendiendo con algunas variaciones para ascender nuevamente en la sílaba nuclear, alineándose con la sílaba tónica (proBLEma). Por último, la curva desciende desde la misma sílaba nuclear trazando una inflexión final simple.

\subsection{Casos particulares}

A continuación, se examinan dos oraciones que presentaron, en el ámbito de la relación acento enfático y foco, un comportamiento disímil a la tendencia general que se describe en la bibliografía especializada.

\subsubsection{Hendida Ho6}

\section{GRÁFICO Y TABLA 7}

Representación melódica de la emisión:

"y es [por eso] que él mantiene en DUDA todavía esta desvinculación"

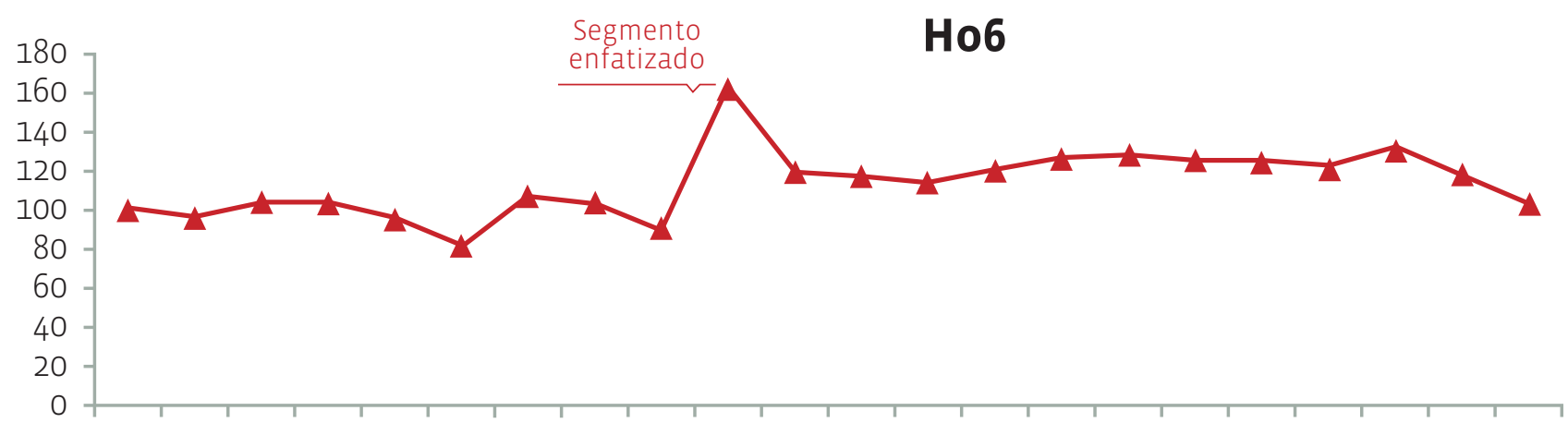

y es por e so que él man tie ne en DU da to da ví a es ta des vin cu la ción 


\begin{tabular}{c|c|c|c|c|c|c|c|c|c|c|c|} 
SHI03 & y es & por & e & so & que él & man & tie & ne & en & DU & da \\
\hline Hz & 180 & 174 & 187 & 185 & 171 & 147 & 185 & 178 & 154 & 265 & 150 \\
\hline$\%$ & 100 & -3 & 8 & -1 & -8 & -14 & 26 & -4 & -14 & 72 & -44 \\
\hline CE & 100 & 97 & 104 & 103 & 96 & 104 & 107 & 104 & 90 & 162 & 119
\end{tabular}

\begin{tabular}{|c|c|c|c|c|c|c|c|c|c|c} 
to & da & ví & $\mathbf{a}$ & es & ta & des & vin & cu & la & ción \\
\hline 147 & 143 & 152 & 162 & 164 & 160 & 158 & 154 & 167 & 147 & 125 \\
\hline-2 & -3 & 6 & 6 & 1 & -2 & -1 & -3 & 9 & -12 & -15 \\
\hline 117 & 114 & 120 & 127 & 128 & 126 & 125 & 122 & 130 & 118 & 104
\end{tabular}

En las estructuras hendidas analizadas en esta sección (gráficos 1 y 2), existe coincidencia entre la cima tonal del trazado melódico con el acento nuclear enfático de los constituyentes en foco; es decir, la estructura sintáctica focalizada se correlaciona con la prominencia acústica. Por el contrario, en el caso de Ho6 (gráfico 7) se observa que la cima tonal no se da en los elementos focalizados, pues si calculamos el valor en $\mathrm{Hz}$ al inicio de la emisión y lo comparamos con el valor más alto alcanzado por la estructura focalizada, solo se registra un ascenso de $8 \%$, que equivale a menos de un semitono. En cambio, se verifica un ascenso tonal muy marcado en el constituyente DUda de la cláusula de relativo, en el que se registra un valor de $265 \mathrm{~Hz}$, equivalente a un ascenso de más de 70\% (6,69ST) en comparación con el resto del trazado melódico. Por lo tanto, la estructura del contorno entonativo de Ho6 se manifiesta con una palabra enfatizada posfocal, en la que coincide la primera cima y núcleo del contorno entonativo, finalizando con un tonema descendente simple.

Este hallazgo constituye una prueba acústica a favor de la distinción entre foco y énfasis como funciones pragmáticas independientes dentro de la dimensión de focalidad. En el caso de la hendida 06, se puede establecer que posee un componente referencial alto (el foco), además de un segmento enfatizado, cuya aparición puede responder tanto a un hecho espontáneo de habla (y, en consecuencia, fortuito) como a un rasgo fonoestilístico o idiosincrásico. Creemos que en HO6 nos enfrentamos a esta última posibilidad, en razón al estilo de habla que caracteriza al sujeto del que se obtuvo la muestra.

\subsubsection{Pseudohendida SHOI}

\section{GRÁFICO Y TABLA 8}

Representación melódica de la emisión:

"El que está complicado en la TABLA es [el cuadro de Puerto Montt]"

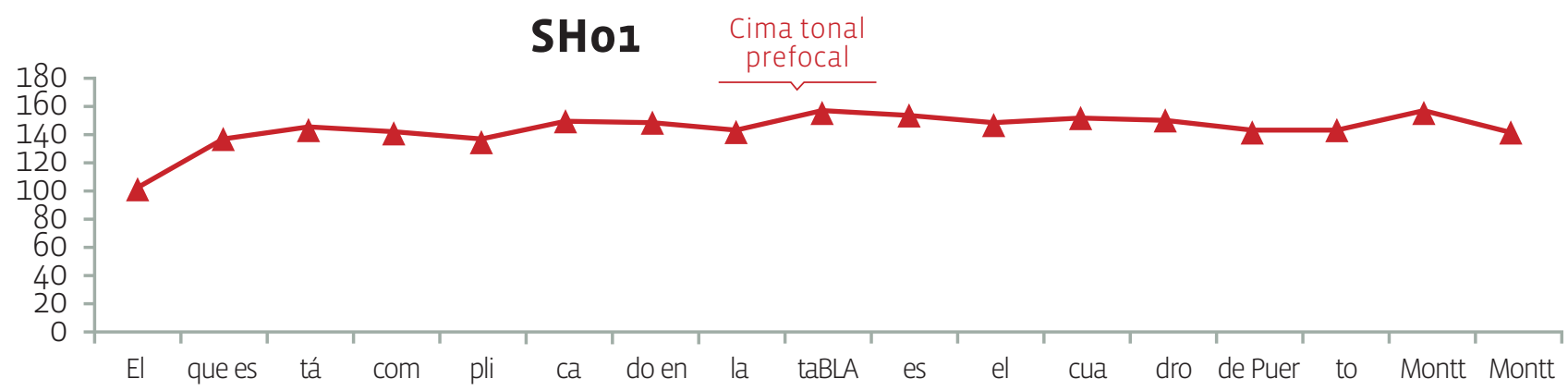




\begin{tabular}{c|c|c|c|c|c|c|c|c|c|c|c|} 
SHI03 & El & que es & tá & com & pli & ca & do en & la & taBLA & es & el \\
\hline Hz & 122 & 164 & 176 & 170 & 161 & 183 & 179 & 168 & 199 & 188 & 177 \\
\hline$\%$ & 100 & 35 & 7 & -3 & -6 & 14 & -2 & -6 & 19 & -6 & -5 \\
\hline CE & 100 & 135 & 142 & 139 & 133 & 147 & 145 & 1 & 157 & 151 & 146
\end{tabular}

\begin{tabular}{|c|c|c|c|c|c} 
cua & dro & de Puer & to & Montt & Montt \\
\hline 185 & 181 & 167 & 170 & 190.7 & 162 \\
\hline 4 & -2 & -8 & 2 & 12 & -15 \\
\hline 150 & 148 & 140 & 142 & 154 & 139
\end{tabular}

En SHol (gráfico 8), el acento enfático del enunciado se ha desplazado hacia la sílaba postónica del constituyente taBLA, de ubicación prefocal. Similar a lo que ocurre en Ho6 (gráfico 7), en SHol no existe coincidencia entre acento enfático y foco, por lo cual vale para este caso la argumentación informativa planteada en el análisis de Ho6. La estructura del contorno de $\mathrm{SHO}$ posee un anacrusis ascendente de $42 \%$ (6ST). El cuerpo de la curva registra variaciones perceptuales poco significativas. La cima tonal se manifiesta desplazada hacia la sílaba postónica de taBLA, que registra un valor de $199 \mathrm{~Hz}(8,4 \mathrm{ST})$. El tonema del contorno presenta un descenso paulatino hasta culminar con una inflexión final circunfleja.

\section{Conclusiones}

Presentamos las conclusiones de acuerdo con los objetivos propuestos para el estudio:

- Caracterizar la fisonomía acústica de las estructuras ecuacionales.

Existe una correlación acústica en el segmento foco por medio de la realización de una cima tonal que, en la mayoría de los casos analizados, se manifiesta en una alineación entre la cima tonal y la sílaba tónica del segmento foco, coincidiendo con hallazgos obtenidos en otros trabajos (Face, 2001 y 2002; Kim y Avelino, 2003; Dorta, 2008) y, por cierto, con el comportamiento esperado, debido a la restricción linear que pesa sobre el acento nuclear y que determina las posiciones iniciales de enunciado como ubicación canónica.

La subdivisión en grupos melódicos para focalizar un constituyente dentro de la emisión se observó como una estrategia común a las tres variedades ecuacionales. La cima tonal puede darse antes o después del límite del grupo melódico.

En cuanto a la duración, se verificó que la sílaba del constituyente en foco tiende a ser la más larga, aunque esto no se dio en todos los casos.

- Determinar diferencias acústicas entre las variedades ecuacionales.

Los rasgos caracterizadores de la construcción ecuacional se dan con mayor intensidad en la variante hendida, por lo cual esta posee la fisonomía acústica más distintiva. El acento nuclear enfático se registra en la primera porción del enunciado, donde se emplaza el foco contrastivo.

Las variantes pseudohendidas manifiestan una prominencia mayor al final de enunciado, fenómeno que las aproxima al comportamiento acústico de oraciones con foco amplio, propio de una estructura no marcada. 
Por su parte, las pseudohendidas inversas exhiben una forma acústica similar a la de una copulativa hendida, sobre todo por el nivel de coincidencia entre acento enfático y constituyente en foco, ubicado al inicio de la emisión.

Por último, el verbo copulativo no presenta ningún tipo de prominencia acústica.

- Establecer correlatos acústicos en las propiedades lexicogramaticales e informativas prominentes de las construcciones ecuacionales.

La prototipicidad focal de la variante hendida manifiesta una mayor correlación entre su estructura sintáctica y su fisonomía acústica.

El carácter acústico menos marcado se observa en la pseudohendida por su carácter de enunciado neutro, deducido esto último de la ubicación del AN en la porción final del grupo melódico.

En cuanto a la pseudohendida inversa, si bien presenta un patrón sintáctico difuso (permite una interpretación focal y atributiva), en contexto de focalidad se realiza con rasgos de prominencia similares al de una estructura hendida prototípica.

El estudio demuestra que la ubicación del AN se distribuye, salvo un par de excepciones, según la linearización esperada de acuerdo con el tipo focal. Al respecto, conviene recordar que el foco contrastivo ocupa posiciones iniciales de la oración donde recibe el acento oportuno.

\section{Bibliografía citada}

ArIel, Mira, 2008: Pragmatics and Grammar, Cambridge y New York: CUP.

Bertuccelli, Marcella, 1996: Qué es la pragmática, Buenos Aires: Paidós.

Burdach, Ana María y Mario Poblete, 2005: "El fenó- meno de focalización en el habla pública de Chile”, Onomázein 11/1, 23-42.

Cantero, Francisco, 2002: Teoría y análisis de la entonación, Barcelona: Edicions de la Universitat de Barcelona.

Cantero, Francisco y Dolors Font, 2009: "Protocolo para el análisis melódico del habla”, Estudios de Fonética Experimental XVIII, 17-32.

CID, Miriam y Lorena Maluenda, 2005: "El alargamiento segmental en el habla pública de Chile: comportamiento prosódico-discursivo", Onomázein $11 / 1,43-55$

Dık, Simon, 1997: The Theory of Functional Grammar. Part 1: The Structure of the Clause, Berlin y New York: Mouton de Gruyter.

DORTA, Josefa, 2008: "La focalización prosódica: funcionalidad en los niveles lingüístico y pragmático", Estudios de Fonética Experimental XVII, 105-138.

Eguren, Luis y Olga Fernández, 2004: Introducción a una sintaxis minimista, Madrid: Gredos.

ERteschik-ShIR, Nomi, 2007: Information structure. The syntax-discourse interface, New York: OUP.

FACE, Timothy, 2001: "Focus and early peak alignment in Spanish intonation", Probus 13, 223-246. FACE, Timothy, 2002: "El foco y la altura tonal en español”, Boletín de Lingüística 17, 30-52.

GutiérRez, Salvador, 1997: La oración y sus funciones, Madrid: Arco Libros.

Halliday, Michael, 2005: On Grammar, London y New York: Continuum.

Halliday, Michael y Cristhian Matthiessen, 2004: An Introduction to Functional Grammar, London: Edward Arnold.

Hengeveld, Kees y J. Lachlan Mackenzie, 2008: Functio- 
nal discourse grammar, Oxford y New York: OUP.

Kım, Sahyang y Heriberto AveLIno, 2003: "An intonational study of focus and word order variation in Mexican Spanish" en Esther Herrera y Pedro Martín Butragueño (eds.): La Tonía, México: El Colegio de México, A.C., 357-374.

Luccl, Vincent, 1983: Etude phonétique du français Contemporain à travers la Variation situationeIle, Grenoble: Université des Langues et Lettres de Grenoble.

Martín Butragueño, Pedro, 2005: "La construcción prosódica de la estructura focal en español" en $V$. Bellosta y G. Knauer (eds.): Variación sintáctica del español: Un reto para las teorías de la sintaxis, Tübingen: Max Niemeyer (Linguistische Arbeiten 49), 117-144.

Martin, James y Peter White, 2005: The Language of Evaluation. Appraisal in English, New York: Palgrave Macmillan.

Martínez, Elena, 1999: Gramática del discurso: foco y énfasis en inglés y en español, Barcelona: Promociones y Publicaciones Universitarias.

NGLE: Real Academia Española y Asociación De Academias De La Lengua Española, 2009: Nueva gramática de la lengua española, Vol. 2, Madrid: Espasa Libros.

Ortiz-LIRA, Héctor, 2000: "La acentuación contextual en español", Onomázein 5, 11-41.

Padilla, Xavier, 2005: Pragmática del orden de palabras, Valencia: Ediciones Universidad de Alicante.

Pinuer, Claudio, 2007: "Análisis sintáctico funcional: principios, perspectivas y casos", Estudios Filológicos 42, 175-190.

Pinuer, Claudio, 2009: "La dimensión de focalidad: conceptualización, instanciación y taxonomías", Revista Signos, Estudios de Lingüística 42 (69), 83106.
Pinuer, Claudio y Teresa Oteiza, 2012a: "Sobre principios, competencia y anulamientos en la linearización oracional", Revista Signos, Estudios de Lingüística, 45(78), 83-99.

Pinuer, Claudio y Teresa Oteíza, 2012b: "El factor linear en la construcción del significado valorativo en el discurso", RILCE, Revista de Filología Hispánica. (Aceptado.)

Rodriguez, Teresa, 2005: Manual de sintaxis del español, Madrid: Castalia.

Sedano, Mercedes, 1990: Hendidas y otras construcciones con ser en el habla de Caracas, Caracas: Ediciones Universidad Central de Venezuela. Sedano, Mercedes, 1995: "Variación de las hendidas en cinco lenguas romances", Anuario de Lingüística Hispánica 11, 353-366.

Sedano, Mercedes, 1996: "Estructura y forma de las hendidas en cinco lenguas románicas: tensión entre economía y claridad", Hispanics Linguistics 8:1, 123-153.

Silva-Corvalan, Carmen, 2001: Sociolingüística y pragmática del español, Washington: Georgetown University Press.

SosA, Juan Manuel, 2003: "Los acentos tonales fonemáticos y el campo tonal en la estructura informativa del español: Datos de un dialecto caribeño" en Esther Herrera y Pedro Martín Butragueño (eds.): La Tonía, México: El Colegio de México, A.C., 403-422.

Van Valin, Robert y Randy Lapolla, 1997: Syntax. Structure, Meaning and Function, Cambridge y New York: CUP. 